\title{
Pengembangan Model Daur Ulang Sampah Plastik Dalam Jaringan Sistem Reverse Logistics
}

\author{
Hendy Suryana \\ Teknik Industri, Fakultas Teknik, Universitas Suryakancana \\ Email: hendies.free@gmail.com
}

Dikirimkan: 12, 2019. Diterima: 12, 2019. Dipublikasikan: 12, 2019

\begin{abstract}
The development of a plastic waste recycling model in the reverse logistics network system is based on the current plastic waste management business activities in Indonesia (in this case the Bekasi and surrounding areas), which is strengthened by some literature on the same business activities in several other countries, such as India. The reverse logistics system in Indonesia is currently one of the best alternatives that can be considered in reducing the limitations of raw material resources. In addition, reverse logistics is proven to provide economic value for business people, then environmental issues become one of the strongest motivations in conducting reverse logistics business. This study aims to develop a model of plastic waste recycling in Indonesia, specifically plastic waste of the compound type LDPE (Low Density Polyethylene) and HDPE (High Density Polyethylene) in the reverse logistics network system and to determine the distribution and transportation network system related to business management activities the plastic garbage. The development of this model can be developed based on empirical data in observing the behavior and characteristics of model variables. The results of the model can produce the total cost of a reverse logistics system in managing plastic waste in Bekasi and its surroundings at Rp. 196,220,250.
\end{abstract}

\section{Keywords - Recycling Model, Reverse Logistics, Network System, Distribution, Transportation}

\begin{abstract}
Abstrak - Pengembangan model daur ulang sampah plastik dalam sistem jaringan reverse logistics didasarkan pada aktivitas bisnis pengelolaan sampah plastik di Indonesia (dalam hal ini wilayah Bekasi dan sekitarnya) saat ini, yang diperkuat dengan beberapa literatur mengenai aktivitas bisnis yang sama di beberapa negara lain, seperti India dan Turki. Sistem reverse logistics di Indonesia, saat ini menjadi salah satu alternatif terbaik yang dapat dipertimbangkan dalam mengurangi keterbatasan sumber daya bahan baku. Selain itu, reverse logistics terbukti dapat memberikan nilai ekonomis bagi para pelaku bisnis, lalu isu lingkungan menjadi salah satu motivasi terkuat dalam melakukan bisnis reverse logistics. Penelitian ini bertujuan untuk mengembangkan model daur ulang sampah plastik di Indonesia, khususnya sampah plastik berjenis senyawa LDPE (Low Density Polyethylene) dan HDPE (High Density Polyethylene) dalam sistem jaringan reverse logistics serta untuk menentukan system jaringan distribusi dan transportasi yang terkait dengan aktivitas bisnis pengelolaan sampah plastik tersebut. Pengembangan model ini dapat dikembangkan berdasarkan data empiris dalam mengamati perilaku dan karakteristik variabel-variabel model. Hasil model dapat dihasilkan total biaya sistem reverse logistics dalam pengelolaan sampah plastik di Bekasi dan sekitarnya sebesar Rp. 196,220,250,-
\end{abstract}

Kata kunci- Model Daur Ulang, Reverse Logistics, Sistem Jaringan, Distribusi, Transportasi.

\section{PENDAHULUAN}

Konsep green supply chain yang berfokus pada peluang implementasi sistem reverse logistics yang merupakan bagian dari sistem logistik konvensional. Implementasi green supply chain memiliki aturan yang disebut dengan dismantlers, yang mana dalam konsep green logistics berfungsi untuk mengoperasikan fungsi tambahan dalam recovery dan recycling. Kemudian konsep uncertainty sangat melekat didalam implementasi sistem reverse logistics yang menjadi tantangan konsep green supply chain. Supply chain konvensional, permintaan yang tidak pasti hanya dipengaruhi oleh tingkat inventori, jumlah produksi, dan logistik. Faktor-faktor ketidakpastian pada reverse supply chain adalah sangat kompleks dibanding pada forward supply chain.

Bagian permintaan yang tidak pasti pada konsep reverse logistics adalah nilai recovery dan nilai landfilling yang sulit diestimasi, keduanya sangat berkontribusi besar pada konsep reverse logistics management. Reverse logistics saat ini menjadi alternatif terbaik yang dapat dipertimbangkan untuk mengurangi keterbatasan 


\section{JMTS|sis Jurnal Media Teknik dan Sistem Industri}

sumber daya bahan baku. Selain itu, reverse logistics terbukti dapat memberikan nilai ekonomis bagi para aktor bisnis, kemudian isu

Reverse logistics dapat dibagi menjadi beberapa kategori [1], telah mengidentifikasi ke dalam lima kategori, termasuk: konsep reverse logistics global, model kuantitatif, logistik (distribusi, pergudangan, dan transportasi), profil perusahaan, dan aplikasi. Baru-baru ini, beberapa peneliti telah berkonsentrasi pada optimasi dan model kuantitatif dalam reverse logistics. Sebagian besar model yang digunakan adalah facility location models, dan mixed integer linear models. Aktivitas utama reverse logistics adalah mengumpulkan produk yang akan diperbarui, dan mendistribusikan kembali bahan-bahan baru yang dihasilkan. Pemembagian jaringan reverse logistics menjadi empat bagian. Jaringan reverse logistics tersebut meliputi: jaringan logistik untuk produk yang dapat digunakan kembali, jaringan logistik untuk remanufaktur, jaringan logistik untuk layanan masyarakat dan regulasi lingkungan oleh pemerintah dan jaringan logistik pribadi untuk pembaruan produk. Tantangan dalam reverse logistics tentu saja memiliki tantangan tersendiri dalam implementasinya. Berbeda dengan forward logistics, maka reverse logistics ada beberapa tantangan sebagai berikut:

1. Peramalan produk kembali menjadi lebih sulit karena tidak ada data mengenai distribusi yang tepat produk End of Life (EOL) untuk kecepatan pengembalian produk sulit untuk diukur.

2. Transportasi cukup sulit karena harus mengumpulkan dari banyak tempat sebelum diubah kembali menjadi rantai pasokan, sehingga dalam menentukan rute produk yang dikembalikan akan menjadi kompleks.

3. Penentuan kualitas pengembalian produk dipengaruhi oleh banyak faktor seperti kondisi ketika produk dikembalikan, siapa yang menggunakan dan bagaimana produk digunakan.

\section{Kerangka Pemikiran}

Kondisi sistem reverse logistics sampah plastik yang terjadi pada industri daur ulang merupakan kerangka pemikiran dalam penelitian ini. Sistem reverse logistics yang terintegrasi dalam pengelolaan sampah plastik dapat memberikan manfaat yang optimal bagi stakeholders secara ekonomis, sosial, dan lingkungan. Studi kasus mengenai sistem reverse logistics pengelolaan sampah plastik di industri daur ulang sampah plastik, karena belum adanya sistem yang terintegrasi dalam pengelolaan lingkungan menjadi motivasi terkuat untuk melakukan reverse logistics,

sampah ini, peneliti mengembangkan model entitas-entitas yang terkait dengan jaringan reverse logistics pengelolaan sampah plastik ini dan mengidentifikasi kapasitas sampah plastik, biayabiaya pada setiap entitas, serta multi aktor dalam jaringan reverse logistics tersebut. Rekayasa model yang terbentuk dapat dibuat suatu perencanaan model keputusan pengelolaan sampah plastik dan perencanaan pola pengumpulan sampah plastik dari pusat-pusat pengumpulan serta perencanaan pendistribusian hasil daur ulang ke distributor, sehingga dari hasil usulan model yang terbentuk diharapkan akan dapat memberikan gambaran sampah plastik bagi para stakeholder.

\section{Pendekatan}

Penelitian ini diharapkan dapat mengembangkan rekayasa model keputusan sistem reverse logistics dalam studi kasus pengelolaan sampah plastik di industri daur ulang di Indonesia. Sistem reverse logistics pengelolaan sampah plastik melibatkan banyak stakeholder yang terintegrasi yang saling berinteraksi satu dengan yang lainnya dalam mencapai tujuan tertentu. Untuk mencapai suatu sistem reverse logistics yang terintegrasi dibutuhkan beberapa pendekatan, yakni diantaramya pendekatan konseptual dan pendekatan matematis. Pendekatan konseptual dalam penelitian ini yang dibutuhkan adalah pendekatan sistem (system of thinking) yang dapat menggambarkan keterkaitan elemen-elemen dalam sistem tersebut sebagai satu kesatuan yang terintegrasi. Selain pendekatan sistem juga diperlukan konsep-konsep yang terpadu, seperti diantaranya konsep Design for Environment (DFE), konsep Green Supply Chain Management, konsep Reverse Logistics, dan konsep Perancangan Sistem. Berdasarkan penyederhanaan permasalahan yang dibahas dan untuk memudahkan pemahaman, maka rekayasa pengelolaan sampah plastik akan dikembangkan model matematis.

\section{HASIL PENELITIAN}

Pengumpulan data parameter model yang dikembangkan dapat diidentifikasi berdasarkan struktur, aliran, dan proses dalam sistem reverse logistics pengelolaan sampah plastik. Jaringan system Reverse logistics dalam aliran dan proses daur ulang sampah plastik dapat diilustrasikan pada gambar 1 di bawah ini, yang dimulai dari entitas konsumen akhir $(\mathrm{k}=1)$, pemulung $(\mathrm{k}=2)$, bank sampah $(\mathrm{k}=3)$, pengumpul/lapak $(\mathrm{k}=4)$, agen/bandar $(\mathrm{k}=5)$, pabrik daur ulang $(\mathrm{k}=6)$, dan 
konsumen produk ekonomis $(\mathrm{k}=7)$.

Pada aliran dan proses sistem reverse logistics membahas mengenai berbagai macam hasil data yang diperoleh penulis, baik bersifat pengumpulan data primer maupun pengumpulan data sekunder. Pengumpulan data primer dilakukan dengan cara melakukan interview dan wawancara secara langsung dilapangan ke setiap pelaku ataupun entitas yang terlibat dalam sistem reverse logistics daur ulang sampah plastik, sedangkan pengumpulan data secara sekunder dilakukan dengan cara mendapatkan langsung informasi dari perusahaan terutama pada entitas pabrik pengolahan daur ulang sampah plastik menjadi produk ekonomis, yakni dalam hal ini perusahaan P.T. Trilion Multiplasindo yang memproduksi bahan baku sampah plastik berjenis plastik Low Density Polyethylene (LDPE) dan High Density Polyethylene (HDPE) yang menghasilkan produk ekonomis dengan nama produk "Tutup Galon JKT". Berdasarkan hasil estimasi dan identifikasi beberapa model parameter, maka dapat diilustrasikan dalam Tabel I data rekapitulasi estimasi parameter model reverse logistics.

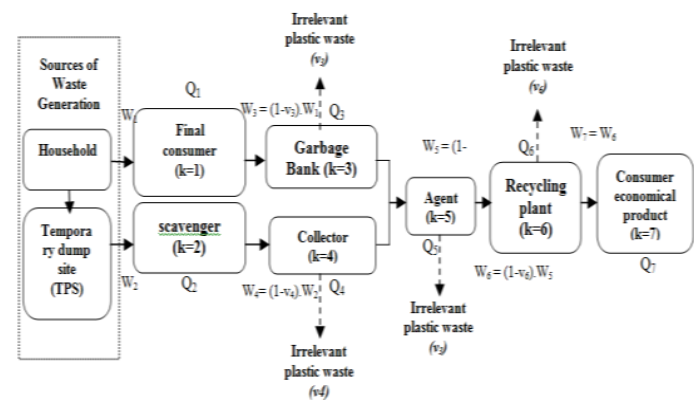

Gambar 1. Aliran Sistem Reverese Logistics Daur Ulang Sampah Plastik Setiap Entitas.

TABEL I

PARAMETER MODEL REVERSE LOGISTICS SAMPAH PLASTIK DAN PRODUK EKONOMIS.

\begin{tabular}{|c|c|c|c|c|c|c|c|c|}
\hline \multirow{2}{*}{$\begin{array}{l}\text { Model } \\
\text { Paraneters }\end{array}$} & \multicolumn{7}{|c|}{ Entity/Shage } & \multirow{2}{*}{ Unit } \\
\hline & $\mathrm{k}=1$ & $k=2$ & $k=3$ & $k=4$ & $k=5$ & $\mathrm{k}=6$ & $\mathrm{k}=$ ? & \\
\hline Wk & $10,000,000$ & $15,000.00$ & $9,000.000$ & $13,500.000$ & $18,000.000$ & $14,400.000$ & $14,400.00$ & $\mathrm{Kg}$ \\
\hline ik & & & 0.10 & 0.10 & 0.20 & 0.20 & & $\%$ \\
\hline CSk & & & 500.00 & 6010.00 & 850.00 & 1,000.000 & & $\mathrm{Rp} / \mathrm{Kg}$ \\
\hline CDk & & & 500.00 & 800.000 & 1,000.0010 & $1,200.000$ & & $\mathrm{Rp} / \mathrm{Kg}_{\mathrm{g}}$ \\
\hline 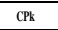 & & & & & & $7,500.000$ & & $\mathrm{Rp} / \mathrm{Kg}$ \\
\hline $\mathrm{fk}$ & & & 0.40 & 0.40 & 1.00 & 1.00 & & $\%$ \\
\hline $\begin{array}{l}\text { TQTk } \\
\end{array}$ & & & $2,000.00$ & $2,0000.010$ & $2,000.100$ & $2,000.000$ & & $\mathrm{Kg}$ \\
\hline QTk & & & 800.00 & 800.00 & $2,0000.010$ & $2,000.000$ & & $\mathrm{Kg}$ \\
\hline $\mathrm{Fk}$ & & & 11 & 17 & 9 & 7 & & Times \\
\hline
\end{tabular}

Dari data parameter model reverse logistics, diperoleh data total kapasitas transportasi truck sampah plastik (TQT $\mathrm{T}_{\mathrm{k}}$ ) pada setiap entitas bank sampah $\quad\left(\mathrm{TQT}_{3}\right), \quad$ kolektor/pengumpul/lapak $\left(\mathrm{TQT}_{4}\right)$, agen/bandar $\left(\mathrm{TQT}_{5}\right)$, dan pabrik daur ulang sampah plastik (TQT6) adalah sebesar @, $2.000 \mathrm{Kg}$, dengan persentase kapasitas transportasi pada setiap entitas berbeda-beda, dikarenakan yang diangkut oleh truck tidak hanya sampah plastik (LDPE dan HDPE), tetapi ada sampahsampah jenis yang lainnya. Untuk bank sampah, persentase sampah plastik yang diangkut $\left(\mathrm{f}_{3}\right)$ adalah sebesar $40 \%$ sampah plastik jenis LDPE dan HDPE, kemudian persentase sampah plastik yang diangkut pada entitas kolektor/pengumpul/lapak ( $\left.f_{4}\right)$ adalah sebesar $40 \%$, tetapi untuk persentase sampah plastik pada entitas agen/bandar adalah sebesar $100 \%$ yang akan didistribusikan ke entitas pabrik daur ulang. Begitu juga untuk entitas Pabrik daur ulang, dikarenakan sampah plastik sudah diolah menjadi produk ekonomis, maka persentase produk ekonomis yang akan didistribusikan ke konsumen akhir produk ekonomis ( $f_{6}$ ) adalah sebesar $100 \%$ produk ekonomis. Berdasarkan data diatas, maka dapat diukur jarak tempuh pengangkutan sampah plastik antar entitas, yang dapat diilustrasikan dengan Tabel II.

TABEL II

JARAK PENGANGKUTAN SAMPAH PLASTIK

\begin{tabular}{|c|c|c|c|c|c|c|c|c|}
\hline \multirow{2}{*}{ Disane } & \multicolumn{7}{|c|}{ Entitiss Sthege } & \multirow{2}{*}{ Lhit } \\
\hline & $k=1$ & $k=2$ & $k=3$ & $k=4$ & $k=5$ & $\mathrm{k}=6$ & $k=1$ & \\
\hline$k=1$ & & & & & & & & Kim \\
\hline$k=2$ & & & & & & & & Kim \\
\hline$k=3$ & & & & 30.00 & 45:500 & & & Kim \\
\hline$k=4$ & & & 30.10 & & 43,000 & & & KIm \\
\hline$k=5$ & & & 45:100 & 4,300 & & 20.00 & & Kim \\
\hline$k=6$ & & & & & 20.00 & & 2,000 & Kim \\
\hline $\mathrm{k}=7$ & & & & & & 29,00 & & Km \\
\hline
\end{tabular}

Selain jarak pengangkutan sampah plastik, diidentifikasi juga biaya transportasi antar entitas pada model reverse logistics daur ulang tersebut. Biaya transportasi antar entitas dapat diestimasi moda angkutan saat kondisi muatan penuh dan kondisi moda angkutan kosong muatan. Untuk data biaya transportasi $\left(\mathrm{CT}_{\mathrm{k}}\right)$ saat kondisi moda transportasi full load dapat dilihat pada Tabel III.

TABEL III

BIAYA TRANSPORTASI $\left(\mathrm{CT}_{\mathrm{K}}\right)$ KONDISI PENUH MUATAN $\left(\mathrm{TQT}_{\mathrm{K}} \cdot \mathrm{F}_{\mathrm{K}}\right)$

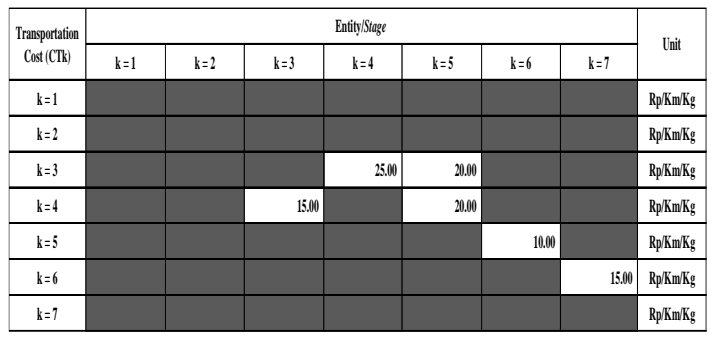

Data biaya transportasi $\left(\mathrm{CT}_{\mathrm{k}}\right)$ pada saat 
kondisi kosong moda transport dapat dilihat pada Tabel IV. Fungsi tujuan model penelitian ini adalah meminimumkan total biaya sistem reverse logistics daur ulang sampah plastik. Berdasarkan dari penjelasan diawal bahwa pada setiap entitas dapat diidentifikasi empat komponen biaya dalam sistem reverse logistics daur ulang sampah plastik, yakni sebagai berikut: Minimum TC $=$ TCT + TCS + TCD + TCP.

TABEL IV

BIAYA TRANSPORTASI (CTK) KONDISI TIDAK ADA MUATAN (KOSONG).

\begin{tabular}{|c|c|c|c|c|c|c|c|c|}
\hline \multirow{2}{*}{$\begin{array}{l}\text { Transportation } \\
\text { Cat (CTk) }\end{array}$} & \multicolumn{7}{|c|}{ Entitystage } & \multirow{2}{*}{ Satuan } \\
\hline & $\mathrm{k}=1$ & $\mathrm{k}=2$ & $k=3$ & $k=4$ & $\mathrm{k}=5$ & $\mathrm{k}=6$ & $k=7$ & \\
\hline$k=1$ & & & & & & & & $\mathrm{Rp} / \mathrm{Km}$ \\
\hline$k=2$ & & & & & & & & $\mathrm{Rp} / \mathrm{Km}$ \\
\hline$k=3$ & & & & & & & & $\mathrm{Rp} / \mathrm{Km}$ \\
\hline$k=4$ & & & & & & & & $\mathrm{Rp} / \mathrm{Km}$ \\
\hline$k=5$ & & & $4,50.000$ & $5,000.000$ & & & & $\mathrm{Rp} / \mathrm{Km}$ \\
\hline$k=6$ & & & & & $4,500.00$ & & & $\mathrm{Rp} / \mathrm{Km}$ \\
\hline$k=7$ & & & & & & $5,000.000$ & & $\mathrm{Rp} / \mathrm{Km}$ \\
\hline
\end{tabular}

\section{Biaya Transportasi $\left(C T_{k}\right)$}

Total Biaya Transportasi (TCT) yang terjadi pada sistem reverse logistics daur ulang sampah plastik khususnya sampah plastik jenis HDPE dan LDPE yakni dapat dirumuskan dibawah ini.

$\mathrm{TCT}=\mathrm{TCT}_{5}+\mathrm{TCT}_{56}+\mathrm{TCT}_{67}$

$\mathrm{TCT}=\left(\left(\frac{W_{4}}{T Q T_{4} \cdot f_{4}} \cdot d_{54} \cdot C T_{54}+W_{4} \cdot d_{45} \cdot C T_{45}\right)+\right.$ $\left.\left(\frac{W_{3}}{T Q T_{3} \cdot f_{3}} \cdot d_{53} \cdot C T_{53}+W_{3} \cdot d_{35} \cdot C T_{35}\right)\right)+$ $\left(W_{5} \cdot d_{56} \cdot C T_{56}+\frac{W_{5}}{T Q T_{5} \cdot f_{5}} \cdot d_{65} \cdot C T_{65}\right) \quad+$ $\left(W_{7} \cdot d_{67} \cdot C T_{67}+\frac{W_{7}}{T Q T_{6} \cdot f_{6}} \cdot d_{76} \cdot C T_{76}\right)$

TCT $=$ Rp. 37,334,250,-/bulan

Keterangan:

$\mathrm{W}_{\mathrm{k}} \quad$ : Demand sampah plastik entitas $\mathrm{k}(\mathrm{Kg})$.

$\mathrm{v}_{\mathrm{k}} \quad$ : Persentase buangan sampah tidak relevan pada entitas $\mathrm{k}(\%)$.

$\mathrm{CT}_{\mathrm{k}}$ : Biaya transportasi sampah plastik dari entitas k ke k+1 (IDR/Kg/Km).

TCT : Total biaya transportasi sampah plastik dari entitas k ke entity k+1 (IDR).

\section{Biaya Pemilahan $\left(C S_{k}\right)$}

Biaya yang berasal dari kegiatan pemilahan, pemisahan, dan pembersihan bahan baku sampah plastik sebelum dilakukan pemrosesan. Kegiatan ini bertujuan untuk memisahkan sampah plastik yang bisa diproses (relevan dan layak) maupun yang tidak bisa diproses. Sampah plastik yang relevan akan digunakan sebagai dasar bahan baku sampah plastik dalam proses daur ulang, sedangkan sampah plastik yang tidak relevan $\left(\mathrm{v}_{\mathrm{k}}\right)$

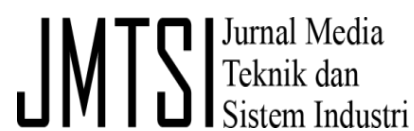

merupakan buangan/kontaminan yang harus dilakukan proses pembuangan (disposal). Biaya Pemilahan $=$ Biaya pemilahan $/ \mathrm{kg}$ sampah plastik pada entitas $\mathrm{k}\left(\mathrm{CS}_{\mathrm{k}}\right)$ dikalikan dengan demand sampah plastik ke entitas $\mathrm{k}\left(\mathrm{W}_{\mathrm{k}}\right)$. Model yang akan diusulkan, bahwa kegiatan pemilahan sampah plastik hanya terjadi di entitas bank sampah $(\mathrm{k}=3)$, kolektor/pengumpul/lapak $(\mathrm{k}=4), \quad$ agen/bandar $(\mathrm{k}=5)$, dan pabrik daur ulang $(\mathrm{k}=6)$.

$\mathrm{TCS}=\mathrm{CS}_{3} \cdot\left(1-\mathrm{v}_{3}\right) \cdot \mathrm{W}_{1}+\mathrm{CS}_{4} \cdot\left(1-\mathrm{v}_{4}\right) \cdot \mathrm{W}_{2}+\mathrm{CS}_{5} \cdot(1-$ $\left.\mathrm{v}_{5}\right) \cdot\left(\mathrm{W}_{3}+\mathrm{W}_{4}\right)+\mathrm{CS}_{6} \cdot\left(1-\mathrm{v}_{6}\right) \cdot \mathrm{W}_{5}$

TCS = Rp. 42.300.000,-/bulan

Keterangan:

$\mathrm{CS}_{\mathrm{k}}$ : Biaya sortir sampah plastik entitas $\mathrm{k}$ $(\mathrm{Rp} / \mathrm{Kg})$.

TCS : Total Biaya Pemilahan pada entitas k (Rp).

Biaya Pembuangan $\left(C D_{k}\right)$

Biaya yang terjadi akibat sejumlah sampah plastik yang tidak layak dan tidak relevan digunakan sebagai bahan proses pengolahan sampah plastik dalam system reverse logistics daur ulang. Biaya pembuangan = Biaya pembuangan $/ \mathrm{Kg}$ sampah plastik entitas $\mathrm{k}\left(\mathrm{CD}_{\mathrm{k}}\right)$ dikalikan dengan persentase sampah plastik yang tidak layak dan tidak relevan pada entitas $\mathrm{k}\left(\mathrm{v}_{\mathrm{k}}\right)$ dikalikan dengan demand sampah plastik entitas $\mathrm{k}$ $\left(\mathrm{W}_{\mathrm{k}}\right)$.

Berdasarkan aktivitas pemilahan, maka akan terjadi pembuangan karena adanya sampah plastik yang tidak layak dan juga tidak relevan. Kegiatan pembuangan terjadi pada entitas: bank sampah $(\mathrm{k}=3), \quad$ kolektor/pengumpul/lapak $\quad(\mathrm{k}=4)$, agen/bandar $(\mathrm{k}=5)$, dan pabrik daur ulang $(\mathrm{k}=6)$. Jadi biaya total pembuangan sampah plastik adalah sebagai berikut:

$$
\begin{aligned}
& \mathrm{TCD}=\mathrm{CD}_{3} \cdot \mathrm{v}_{3} \cdot \mathrm{W}_{3}+\mathrm{CD}_{4} \cdot \mathrm{v}_{4} \cdot \mathrm{W}_{4}+\mathrm{CD}_{5} \cdot \mathrm{v}_{5} \cdot \mathrm{W}_{5}+ \\
& \mathrm{CD}_{6} \cdot \mathrm{v}_{6} \cdot \mathrm{W}_{6} \\
& \mathrm{TCD}=\mathrm{Rp} .8 .586 .000, \text {, } / \text { bulan }
\end{aligned}
$$

Keterangan:

$\mathrm{CD}_{\mathrm{k}}$ : Biaya disposal sampah pada entitas $\mathrm{k}$ ( $\mathrm{Rp} / \mathrm{Kg})$.

TCD : Biaya disposal sampah pada entitas $\mathrm{k}$ ( $\mathrm{Rp} / \mathrm{Kg})$.

\section{Biaya Pengolahan/Produksi $\left(\mathrm{CP}_{k}\right)$}

Biaya proses sistem reverse logistics daur ulang sampah plastik dan memproduksi produk ekonomis. Biaya pengolahan terdiri dari komponen utama, yakni biaya pengolahan bahan baku sampah plastik $\left(\mathrm{CP}_{\mathrm{k}}\right)$. Biaya Pengolahan = Biaya pengolahan bahan baku sampah plastik pada entitas $\mathrm{k}\left(\mathrm{CP}_{\mathrm{k}}\right)$ dikalikan dengan demand sampah plastik yang dihasilkan dan dikirimkan ke entitas 
berikutnya $\left(\mathrm{W}_{\mathrm{k}}\right)$. Biaya pengolahan terjadi hanya pada entitas Pabrik reverse logistics daur ulang sampah plastik $(\mathrm{k}=6)$ yang memproses dan mengolah sampah plastik menjadi produk yang bernilai ekonomis, yakni produk "Tutup Galon JKT" yang kemudian didistribusikan ke konsumen akhir/produk ekonomis. Sistem reverse logistics daur ulang sampah plastik terdiri dari komponen biaya pengolahan bahan baku sampah plastik $\left(\mathrm{CP}_{6}\right)$. Jadi total biaya pengolahan sampah plastik adalah sebagai berikut:

$\mathrm{TCP}=\mathrm{CP}_{6} \cdot \mathrm{W}_{6}$

$\mathrm{TCP}=108.000 .000,-/$ bulan

Keterangan:

$\mathrm{CP}_{\mathrm{k}} \quad$ : Biaya produksi sampah plastik entitas $\mathrm{k}$ $(\mathrm{Rp} / \mathrm{Kg})$.

TCP : Total biaya pengolahan sampah plastik (Rp).

Model matematis fungsi objektif sistem reverse logistics dengan berdasarkan biaya transportasi, biaya pemilahan, biaya pembuangan, dan biaya pengolahan adalah sebagai berikut:

Minimum TC $=(\mathrm{TCT})+(\mathrm{TCS})+(\mathrm{TCD})+(\mathrm{TCP})$

Minimum $\quad \mathrm{TC}=\left(\left(\frac{\mathrm{W}_{4}}{\mathrm{TQT}_{4} \cdot \mathrm{f}_{4}} \cdot \mathrm{d}_{54} \cdot \mathrm{CT}_{54}+\right.\right.$ $\left.\mathrm{W}_{4} \cdot \mathrm{d}_{45} \cdot \mathrm{CT}_{45}\right)+\left(\frac{W_{3}}{T Q T_{3} \cdot f_{3}} \cdot d_{53} \cdot C T_{53}+\right.$ $\left.\left.W_{3} \cdot d_{35} \cdot C T_{35}\right)\right)+\left(W_{5} \cdot d_{56} \cdot C T_{56}+\right.$ $\left.\frac{W_{5}}{T Q T_{5} \cdot f_{5}} \cdot d_{65} \cdot C T_{65}\right)+\left(W_{7} \cdot d_{67} \cdot C T_{67}+\right.$ $\left.\frac{W_{7}}{T Q T_{6} \cdot f_{6}} \cdot d_{76} \cdot C T_{76}\right)+\left(\mathrm{CS}_{3} \cdot\left(1-\mathrm{v}_{3}\right) \cdot \mathrm{W}_{1}+\mathrm{CS}_{4} \cdot(1-\right.$ $\left.\left.\mathrm{V}_{4}\right) \cdot \mathrm{W}_{2}+\mathrm{CS}_{5} \cdot\left(1-\mathrm{v}_{5}\right) \cdot\left(\mathrm{W}_{3}+\mathrm{W}_{4}\right)+\mathrm{CS}_{6} \cdot\left(1-\mathrm{v}_{6}\right) \cdot \mathrm{W}_{5}\right)+$ $\left(\mathrm{CD}_{3} \cdot \mathrm{v}_{3} \cdot \mathrm{W}_{3}+\mathrm{CD}_{4} \cdot \mathrm{v}_{4} \cdot \mathrm{W}_{4}+\mathrm{CD}_{5} \cdot \mathrm{v}_{5} \cdot \mathrm{W}_{5}+\right.$ $\left.\mathrm{CD}_{6} \cdot \mathrm{v}_{6} \cdot \mathrm{W}_{6}\right)+\left(\mathrm{CP}_{6} \cdot \mathrm{W}_{6}\right)$

Minimum TC = Rp. 196.220.250,-/bulan

\section{KESIMPULAN}

Optimasi model daur ulang sampah plastik dalam sistem jaringan reverse logistics di Indonesia, dihasilkan model matematis linier programing dengan fungsi tujuan untuk meminimasi total biaya sistem reverse logistics daur ulang berdasarkan variabel keputusan, antara lain: jumlah dan kapasitas sampah plastik, lokasi, dan rute transportasi. Komponen biaya dalam sistem reverse logistics daur ulang tersebut adalah diantaranya: biaya transportasi $\left(\mathrm{CT}_{\mathrm{k}}\right)$, biaya pemilahan $\left(\mathrm{CS}_{\mathrm{k}}\right)$, biaya pembuangan $\left(\mathrm{CD}_{\mathrm{k}}\right)$, dan biaya pengolahan/produksi $\left(\mathrm{CP}_{\mathrm{k}}\right)$. Solusi kinerja model sistem reverse logistics daur ulang sampah plastik ditunjukkan dengan total biaya sistem minimum sebesar Rp. 196.220.250,-/bulan yang diimplementasikan pada kondisi sistem eksisting.

\section{REFERENSI}

[1] Dowlatshahi S. 2000. Developing a Theory of Reverse Logistics.Interfaces, 30(3): 143-155. 